\title{
A Survey on Agricultural Application based on Android
}

\author{
Navya S*, Khateeja Ambareen, S. Meenakshi Sundaram \\ Department of Computer Science and Engineering, GSSS Institute of Engineering and \\ Technology for Women, Mysuru
}

DOI: https://doi.org/10.21467/proceedings.1.35

* Corresponding author email: reach2navya@ gmail.com

\begin{abstract}
In the agricultural domain, the main challenge is to present the new information and research to the farmers so that they can leverage the power of ICT to improve their agricultural practices and there by the production. An Agro advisory system helps to bridge the gap between farmers and the agriculture domain experts. The system consists of three basic components: Ontology, Web Services, and Mobile Application Development. The ontology maintains domain knowledge required for answering farmer queries. The ontology contains information regarding crop, soil, cultivation process, disease, pest, and other relevant information. This paper discusses about the Agro Advisory system, survey related to it and some of the applications and benefits regarding Agricultural Application based on Android.

Index Terms- Ontology, Web services, ICT->Information communication technology.
\end{abstract}

\section{INTRODUCTION}

An Agro advisory system helps to bridge the gap between farmers and the agriculture domain experts [1]. India is one of the leading countries in the field of agriculture, where near about $60 \%$ of population lives in rural areas, engaged in farming business. Information for this business plays an important role, and is needed for different purposes. The agriculture scenario is becoming more complex, and the need to access and store information by the farmers has also increased. The farmers require a wide range of information to support their farming businesses and livelihoods. Following are some examples of information for the needs of Indian farmers:

- Agriculture related news: Most of the Indian farmers are unaware of agricultural information like latest technologies, developments and research.

- Commodity prices in the markets: Indian farmers are growing different types of commodities. Farmers having access to commodity price information will be able to negotiate with traders or buyers for best prices.

- Markets to sell the commodity: Frames are unaware of the best markets in which they can sell their commodities. [2]

(C) 2018 Copyright held by the author(s). Published by AIJR Publisher in Proceedings of the $3^{\text {rd }}$ National Conference on Image Processing, Computing, Communication, Networking and Data Analytics (NCICCNDA 2018), April 28, 2018.

This is an open access article under Creative Commons Attribution-NonCommercial 4.0 International (CC BY-NC 4.0)

license, which permits any non-commercial use, distribution, adaptation, and reproduction in any medium, as long as the original work is properly cited. ISBN: $978-81-936820-0-5$ 
This paper discusses about the app for mobile device like android Smartphone, etc. which will be having the services like weather information, soil health status, cropping pattern, location specific crop disease, etc. It will be a better GUI based app form which the farmer can understand i.e. they do not have difficulties to find answers for their question. They can chat with experts; they can call and ask the questions to experts, etc facilities we can provide in this app. This app ecosystem provides an integrated view of the farmers profile, farming history, and the required farm parameters on a console at a remote location to an expert. Farmers can also send pictures of their crops and pests captured with mobile phone cameras, sensors provide farm specific soil and crop data, weather stations provide microclimate details and voice based querying system gives freedom to the farmers to ask any query in their local (natural) language. [1]

\subsection{INFORMATION COMMUNICATION TECHNOLOGY (ICT) [4]: -}

ICT provides the information related to agriculture to Indian farmers at very reasonable and affordable cost. The most recent area of ICT is cloud computing which provides the services and tools on pay-per-use basis. The farmers whenever required any information send the query for the appropriate cloud service and after analysis and processing of the request final result are passed back to the farmer. The request may be related to the latest farming, pest control knowledge and the entire process from production, distribution to consumption [5]. Data related to yield and quality, soil properties and remote sensing are composed from various sources stored to GIS databases and evaluated through geostatistical methods so that it is helpful to the farmers for management zones and decision support systems [6]. Moreover, eAgriculture contributes in the agriculture development as well as rural development.

\section{$1.2 \quad$ AGRO-ADVISORY SYSTEM ARCHITECTURE}

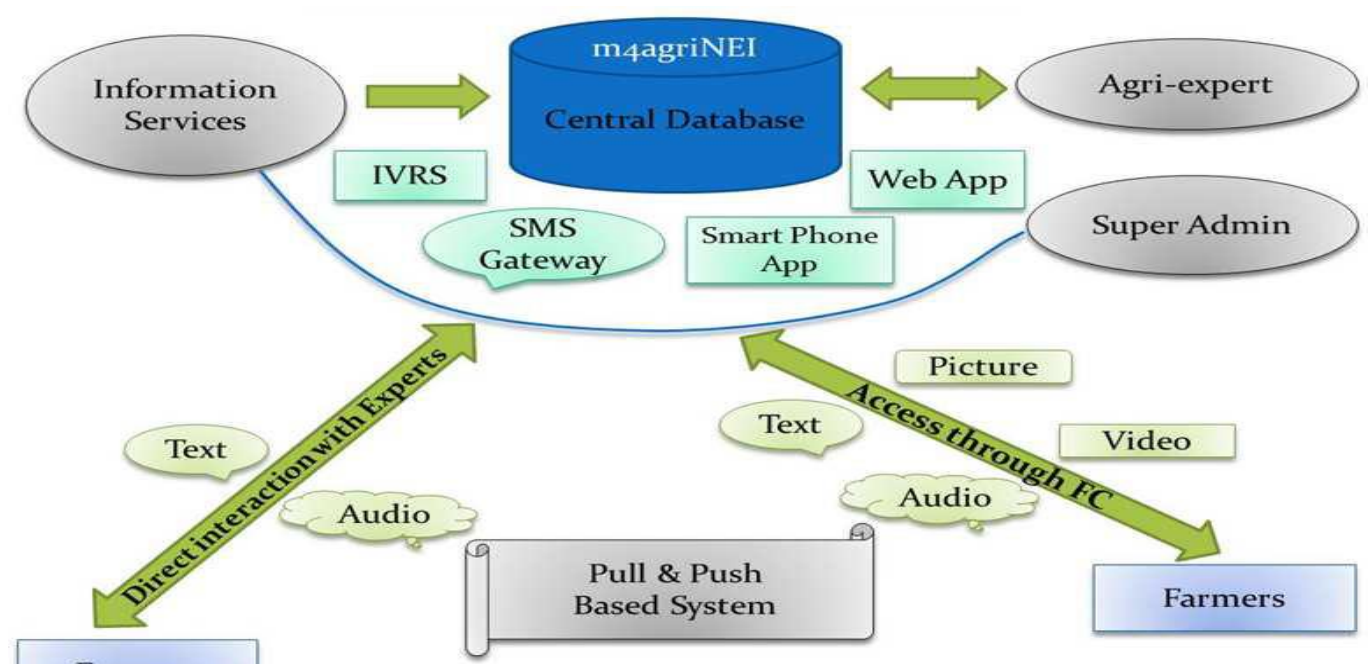

Farmers

Fig. 1. Agro-advisory System Architecture

Proceedings of the $3^{\text {rd }}$ National Conference on Image Processing, Computing, Communication, Networking and Data Analytics (NCICCNDA 2018) 
A Survey on Agricultural Application based on Android

A multimedia agro advisory laboratory was developed, which is equipped with state of art information communication tools and gadgets to establish the connectivity through Interactive Voice Response System (IVRS), smart phone and cell phones with farmers and the experts in laboratory. Agro-associates from different disciplines of agricultural sciences, horticultural sciences, animal sciences and fisheries sciences were employed, who works as Level-I expert to provide need based advisory services to the farming community. These agroassociates also obtain suggestions and advisory from scientists from different research stations and agricultural university, who are involved as Level-II expert. To develop a link between the farming community and the experts in laboratory, some field coordinators were employed in area-wise taking some villages together. These field coordinators are equipped with smart phone with internet connection and visit a village at least twice in a week to help the farmers, who are not well-versed with cell phone technology, to collect field-based problem and send it to the lab, to assess the need of the farming communities, to organize need based training for farming communities etc.

\section{LITERATURE SURVEY}

With mobile handsets being used in nearly every country and community, the development of applications for them offers uses that extend well beyond voice and text communications. Mobile applications for agricultural and rural development could provide the most economic, practical, and accessible routes to information, markets, governance, and finance for millions of people who have been excluded from their use. [3] Agriculture plays an important role in Indian economy due to the large rural population. Because of this, in the current age more/large amount of data related to agriculture like weather, soil, etc. being collected by different sources. But this all data is not used efficiently by the farmers due to lack of mediums for that information to flow. In agriculture domain, the farmers might have queries regarding soil, crop, diseases, weather, etc. Based on such observations and situations, this section discusses about the development of a system that can help to bridge the gap between farmers and expert and able to answer basic queries of the farmers that might help them in improving their farming practices. [1]

\section{APPLICATIONS AND BENEFITS [1]}

1. The gap between the farmer's and the experts will be reduced.

2. Time required giving experts advice will get reduced because now experts don't need to visit each and every farm. Only just by reading queries experts give their advices to each farmer's in personal.

3. Farmers can also put their query in on web forum where experts can answer them and thousands of farmers with same query an read answers given by them and can get benefited. 
4. Farmers will also get weather notifications so that they will be aware of any future weather conditions. Now they can protect their farms from upcoming weather disasters.

5. Graphs can describe situations better than numbers. So that when any big diseases get spread over large areas. Then just by looking at graphs. Experts will get to the conclusions in very less time and can give their expert advice so that many farms will get saved.

\section{CONCLUSION}

As discussed in this paper if apps are developed in Android to reduce the gap between Farmers and Agriculture experts it will be helpful for in many dimensions. They are as follows:

- Understand the advanced Agricultural methods.

- To know about the new equipments and tools to reduce the human effort.

- To understand the market status for their crops.

- To know innovative ideas in Agricultural domain to implement.

- This will come with a revolution in farming and many farmers will get optimum advice for their crop and the problem of lack of knowledge of farming will get solved.

- Also, it gives proper information about the fertilizers for the plants and in what amount that can be added to the crops when they plant and when they cut the plants or crops, all these information can be provided through this app.

\section{References}

[1] Patil Akshay ${ }^{1}$, Kulange Rohit ${ }^{2}$, Mehta Suyash ${ }^{3}$, Katkar Abhishek ${ }^{4}$,Prof. Mukesh Rangdal ${ }^{5}$, "Android Agro Advisory System” International Journal of Engineering and Techniques - Volume 1 Issue 6, Nov - Dec 2015

[2] Lalit Ashok Boraste. "An Android application for Indian Farmer's" Dissertation submitted in partial fulfilment for the degree of Master of Science in Advanced Computing Computing Science and Mathematics University of Stirling

[3] Vinita Patil ${ }^{1}$, Snehal Payer ${ }^{2}$, Trupti Teli ${ }^{3}$, Prof Suja Jaychandran ${ }^{4}$ "Decision Support System for Agriculture Management" International Journal of Emerging Trends in Science and Technology - DOI: http://dx.doi.org/10.18535/ijetst/v3i012.01

[4] P. Satpute, and O. Tembhurne, "A Review of Cloud Centric IoT Framework for Supply Chain Management in Precision Agriculture", International Journal of Advance Research in Computer Science and Management Studies, Vol. 2 (11), 2014.

[5] S. Nandyal and P. B. Kolhapure, "Design and Implementation of Framework for AgriCloud", International Journal of Agriculture Innovations and Research, Vol. 4 (2), pp. 2319-1473, 2015.

[6] Harjinder Kaur, Major Singh Goraya, "A Scenario of IT based Agriculture Projects in India”, International Journal of Advanced Research in Computer Science

[7] Biswajit Lahiri1 ${ }^{1}$, Swapnali Borah ${ }^{2}$, Natasha R. Marak ${ }^{3}$ and Thiruchirapalli Sudarshan Anurag ${ }^{4}$, "Development of mobile phone based agro-advisory system through ICT mediated extension approach in North-eastern himalayan region of India", Journal of Applied and Natural Science 9 (3): 1808 -1814 (2017).

Proceedings of the $3^{\text {rd }}$ National Conference on Image Processing, Computing, Communication, Networking and Data Analytics (NCICCNDA 2018) 